\title{
Morphology, Structure, and Properties of Conductive Polylactide Fibers Prepared Using Polyvinyl Acetate and Multiwalled Carbon Nanotubes
}

\author{
Qingsheng Liu ${ }^{1,2,3, *}$, Yuqi Zhou ${ }^{1}$, Ying Shen ${ }^{1}$, Yuhao Li ${ }^{4}$, Haiyang Guo ${ }^{5}$, Bingyao Deng ${ }^{1}$ and \\ Yonggui $\mathrm{Li}^{2, *}$ \\ 1 Key Laboratory of Eco-Textiles, Ministry of Education, Jiangnan University, Wuxi 214122, China \\ 2 Fujian Key Laboratory of Novel Functional Textile Fibers and Materials, Minjiang University, \\ Fuzhou 350108, China \\ 3 Shenghong Group Co., Ltd., Shengze 215228, China \\ 4 China Nonwovens \& Industrial Textiles Association, Beijing 100020, China \\ 5 Jiangsu Doway New Materials Science \& Technology Co. Ltd., Suqian 223800, China \\ * Correspondence: qsliu@jiangnan.edu.cn (Q.L.); lygwxjd@sina.com (Y.L.); \\ Tel.: +86-0510-8591-2007 (Q.L.); +86-0591-8376-0411 (Y.L.); Fax: +86-0510-8591-2009 (Q.L.)
}

Received: 26 August 2019; Accepted: 6 October 2019; Published: 9 October 2019

\begin{abstract}
Two kinds of conductive polylactide fibers-polylactide pre-oriented yarns (PLA-POY) and PLA-drawn textured yarns (PLA-DTY) are prepared by coating method using ethyl acetate as solvent, multiwalled carbon nanotubes (MWCNTs) as conductive filler, and polyvinyl acetate (PVAc) as dispersing agent and coating agent. The PLA fibers are characterized by scanning electron microscope (SEM), Fourier-transform infrared spectroscopy (FTIR), differential scanning calorimetry (DSC), resistance meter, and tensile test. The results show that PLA-POY and PLA-DTY have been coated successfully by PVAc and MWCNTs. After PLA-POY fibers are treated by ethyl acetate, the highly porous structures form because of swelling and the subsequent solvent-induced crystallization of PLA-POY fibers with low crystallinity. This causes the tensile force to decrease. However, PVAc can improve the tensile force of the treated PLA-POY fibers. For PLA-DTY fibers, the effect of ethyl acetate on surface morphology is small. Therefore, the treated PLA-DTY fibers own higher tensile properties than original PLA-DTY fibers due to the existence of PVAc. With the increase of PVAc and MWCNTs, the conductive properties of the PLA fibers will increase. The electrical conductivity of PLA-POY and PLA-DTY fibers can reach 0.53 and $0.13 \mu \mathrm{s} / \mathrm{cm}$, respectively.
\end{abstract}

Keywords: polylactide fibers; conductive properties; multiwalled carbon nanotubes; polyvinyl acetate; ethyl acetate

\section{Introduction}

Polylactide (PLA) is a type of biodegradable polyester with thermoplastcity, biodegradability, and biocompatibility [1,2]. PLA has been extensively used for fiber materials due to its similarity with polyethylene terephthalate (PET) fibers, ecofriendly nature, and ease of processing [3]. The melt-spinning method is optimal for manufacturing PLA fibers because of its thermoplastcity [3] and a wide melt-processing window.

The effects of processing conditions on the structure and properties of melt-spun PLA fibers have been studied widely [4-6]. Especially, Liu et al. [3] studied the effect of air drawing on structure and properties of PLA fibers. Solarski et al. [7] introduced plasticizer and clay to PLA and manufactured PLA fibers by melt-spinning process. The obtained PLA fibers presented an improvement in thermal and shrinkage properties. Polylactide/poly (3-hydroxybutyrate-co-3-hydroxyvalerate) (PLA/PHBV) 
blend fibers were manufactured via the conventional two-step melting-spinning and hot-drawing process by Li et al. [8] Compared with traditional PLA fibers, the prepared fibers showed significantly reduced boiling water shrinkages and superior softness. Hufenus et al. [9] prepared PLA/PHBV core-sheath bicomponent fibers. When the PLA was chosen as the raw material of sheath layers, the fibers could be successfully spun. However, when the PHBV was used as the raw material of sheath layers, it was difficult to produce PLA/PHBV bicomponent fibers. The tensile properties of bicomponent fibers with a PHBV core and a PLA sheath were determined by PLA. Zhang et al. [10] prepared high-performance PLA fibers via tailoring crystallization with the aid of an active nucleating agent (NA). Compared with neat PLLA fibers, a prominent increase of $78 \%$ in tensile strength and a substantial decline of $1069 \%$ in boiling water shrinkage were achieved in the obtained fibers with 0.3 wt.\% NA [10].

Although melt-spun PLA fibers have been widely explored, few studies [11,12] on functional PLA fibers have been performed. It is well known that conductive fibers are important and highly functional, and that they can be used as flexible electronic devices including solar cells, displays, radio identification, sensor tapes, capacitors, and batteries [13,14]. Rentenberger et al. [12] prepared conductive PLA/poly( $\varepsilon$-caprolactone)/multiwalled carbon nanotubes (PLA/PCL/MWCNTs) fibers using the double percolation method. The double percolation method can efficiently prepare conductive fibers. Conductive fillers are added into immiscible polymer blends. The two phases in immiscible polymer blends form a co-continuous blend morphology. Conductive fillers are selectively located in one of the two polymer matrices, or their interface, so that the percolation threshold of conductive fillers decreases [15]. However, the double percolation method is complicated.

Coating is thought as a simple and efficient way to manufacture conductive fibers. However, for coating, the key difficulties include the uniform dispersity of the conductive fillers and the strong bonding force between coating agent and fiber. Here, the two kinds of conductive polylactide fibers, including PLA pre-oriented yarns (PLA-POY) and PLA-drawn textured yarns (PLA-DTY), were prepared by coating method using ethyl acetate as solvent, multiwalled carbon nanotubes (MWCNTs) as conductive filler, and polyvinyl acetate (PVAc) as dispersing agent and coating agent. PVAc can make unmodified MWCNTs disperse uniformly in ethyl acetate. Moreover, PVAc is compatible completely with PLA, which is a good coating agent for PLA fibers. The strong bonding force will form between PVAc and PLA fibers. Ethyl acetate has low toxicity, and it can be used an additive in foods and drugs to improve their flavor. In addition, the morphology, chemical structure, thermal behavior, conductive properties, and tensile properties of the prepared conductive PLA fibers were characterized by SEM, FTIR, differential scanning calorimetry (DSC), resistance meter, and tensile test.

\section{Experimental Details}

\subsection{Materials}

Polyvinyl acetate (PVAc) $\left(M_{\eta}=3.0 \times 10^{5} \mathrm{~g} / \mathrm{mol}\right)$ was obtained from Yantai Nuoda Chemical Co., Ltd. (Yantai, China). Multiwalled carbon nanotubes (MWCNTs) with diameter of 40-60 nm and length of less than $2 \mu \mathrm{m}$ were purchased from Shenzhen Nanotech Port Co., Ltd. (Shenzhen, China). Ethyl acetate was purchased from Sinopharm Chemical Reagent Co., Ltd. (Shanghai, China). Polylactide pre-oriented yarns (PLA-POY) and drawn textured yarns (PLA-DTY) were manufactured by Hengtian Changjiang Biological Materials Co., Ltd. (Changshu, China). Each PLA-POY contains 72 fibers. The diameter of each fiber in PLA-POY is $\sim 20 \mu \mathrm{m}$. PLA-DTY was prepared by drawing and twisting/untwisting simultaneously PLA-POY. The diameter of each fiber in PLA-DTY is $\sim 14 \mu \mathrm{m}$.

\subsection{The Preparation of Conductive PLA Fiber}

First, PVAc was added to ethyl acetate and dissolved by stirred for $3 \mathrm{~h}$ with a magnetic stirrer to prepare PVAc in ethyl acetate solution. Second, the required amounts of MWCNTs were added into PVAc in ethyl acetate solution, stirred for $30 \mathrm{~min}$ by a magnetic stirrer, and then sonicated for $2 \mathrm{~h}$ to 
obtain the suspension of MWCNTs and PVAc in ethyl acetate. Here, the concentration of MWCNTs and PVAc in ethyl acetate is $2-10$ and $10-50 \mathrm{mg} / \mathrm{mL}$, respectively. Last, conductive PLA fibers were prepared by coating method; the coating method is shown in Figure 1. The temperature of the water bath in the ultrasonic cleaner was room temperature. The take-up speed of conductive fibers was $\sim 1$ $\mathrm{m} / \mathrm{min}$. The obtained conductive fibers were dried naturally in fume hood. The treated PLA-POY and PLA-DTY fibers are denoted by OCxPy and TCxPy, respectively. Here, the letter "O" in OCxPy and the letter " $\mathrm{T}$ " in TCxPy stand for PLA-POY and PLA-DTY, respectively. $\mathrm{C}$ and $\mathrm{x}$ stand for MWCNTs and the concentration of MWCNTs, respectively. P and y stand for PVAc and the concentration of PVAc, respectively.

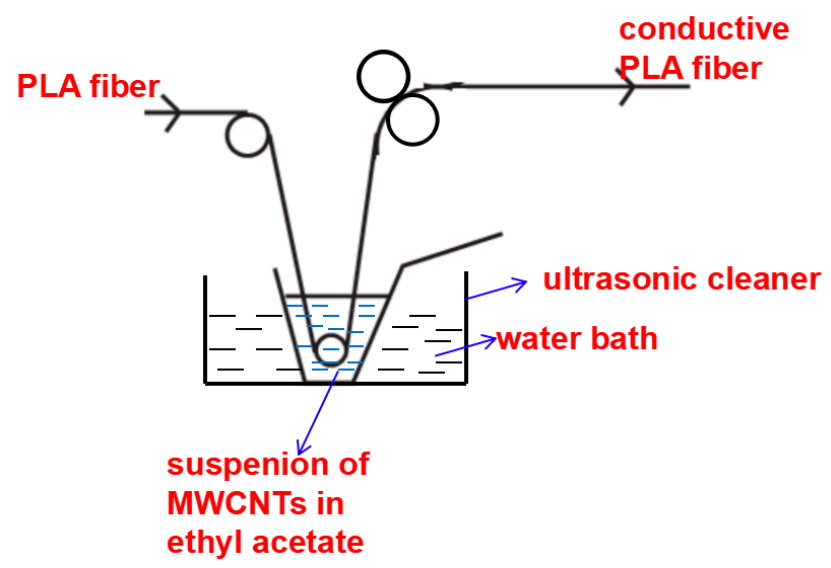

Figure 1. The schematic of the coating method.

\subsection{Differential Scanning Calorimetry}

The crystallization behaviors and melting behaviors of the samples were characterized by differential scanning calorimetry that used a DSC Q200 (TA Instruments ${ }^{\circledR}$, Inc., New Castle, DE, USA). Nitrogen was used at a flow rate of $50 \mathrm{~mL} / \mathrm{min}$. The instrument was calibrated with In and $\mathrm{Pb}$. The weight of the samples was between 4 and $6 \mathrm{mg}$. Each sample was heated from 0 to $200{ }^{\circ} \mathrm{C}$ at $10^{\circ} \mathrm{C} / \mathrm{min}$.

\subsection{Scanning Electron Microscope}

Scanning electron microscopy (SEM) measurements of the longitudinal surface and cross section of fibers were carried out by a Model SU1510 scanning electron microscope (Hitachi, Tokyo, Japan). The samples were sputtered with gold before the SEM observation. The morphologies of the cross sections of samples were observed at a working voltage of $5 \mathrm{kV}$. Here, the fiber bundles first are embedded by using collodion. Then, cross-section slices were prepared by using Y172 Hardy's thin cross-section device (Changzhou Depu Textile Technology Co., Ltd., Changzhou, China).

\subsection{Fourier Transform Infrared-Attenuated Total Reflection Spectroscopy}

The spectra of Fourier transform infrared-attenuated total reflection (FTIR-ATR) were recorded on a Nicolet FTIR spectroscope (Nexus 670, Waltham, MA, USA). Each spectrum was recorded with a total of 16 scans from 4000 to $500 \mathrm{~cm}^{-1}$; each scan had a resolution of $4 \mathrm{~cm}^{-1}$ at room temperature. The spectra were subtracted against a background air spectrum. OMNIC Nicolet Software (version 8.1) was used for spectra analysis.

\subsection{Conductive Properties}

The conductive properties of the treated PLA fibers with high resistivity were tested by Keithley 65167B high resistance meter (Cleveland, OH, USA). The conductive properties of the treated PLA fibers with low resistivity were tested using a TENMARS TM-87 digital multimeter (Taipei, Taiwan). 
The length of the tested fibers is $0.08 \mathrm{~m}$. The electrical resistivity of the untreated PLA fibers was characterized by a YG321 fiber-specific resistance tester. Five gram samples were used every time. The tests were carried out at room temperature with relative humidity of $65 \%$.

\subsection{Tensile Test}

The tensile properties of PLA fibers were determined on an YG061-1500 yarn tensile tester (Laizhou Electron Instrument Co., Ltd., Laizhou, China) at room temperature. The cross-head speed and gauge length were $250 \mathrm{~mm} / \mathrm{min}$ and $250 \mathrm{~mm}$, respectively, and the pre-tension was $5 \mathrm{cN}$.

\section{Results and Discussion}

\subsection{Morphology of PLA Fibers}

Figure 2 illustrates the SEM photographs of the PLA-POY fibers treated by MWCNTs and PVAc in ethyl acetate. The SEM photographs in Figure 2a,b show that the surface of PLA-POY fibers is smooth and the cross section is round. However, when the PLA-POY fibers are treated by ethyl acetate, a large number of pores appear in the surface and cross-section of PLA-POY, which is shown in Figure 2c. The highly porous structure formed because of swelling and subsequent solvent-induced crystallization of PLA-POY fibers with low crystallinity [11]. Figure $2 \mathrm{~d}-\mathrm{f}$ reveals that in PLA-POY fibers treated by MWCNTs and PVAc in ethyl acetate with the concentration of $8 \mathrm{mg} / \mathrm{mL}$ MWCNTs and $40 \mathrm{mg} / \mathrm{mL}$ PVAc, the single fibers the of multifilaments adhere to each other. In addition, the MWCNTs are coated on the surface of PLA-POY fibers, which can be observed in Figure 2e,f.
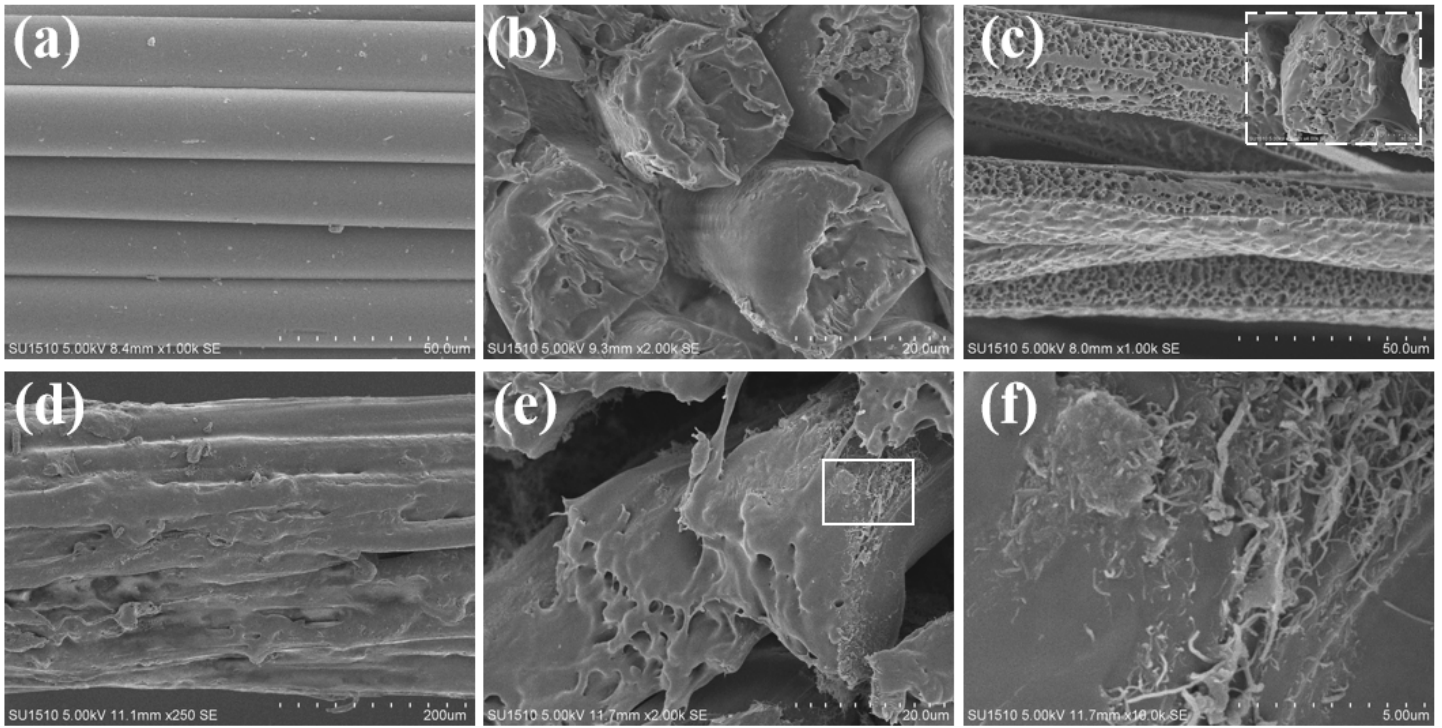

Figure 2. The SEM photographs of PLA pre-oriented yarns (PLA-POY) fibers treated by multiwalled carbon nanotubes (MWCNTs) and PVAc in ethyl acetate. (a,b) Original PLA-POY fibers. (c) PLA-POY fibers treated by ethyl acetate for $30 \mathrm{~min}$ at room temperature. (d,e) PLA-POY fibers treated by MWCNTs and PVAc in ethyl acetate with concentration of $8 \mathrm{mg} / \mathrm{mL}$ MWCNTs and $40 \mathrm{mg} / \mathrm{mL}$ PVAc. (f) The enlargement of the part in white square frame of panel e.

Figure 3 shows the SEM photographs of PLA-DTY fibers treated by MWCNTs and PVAc in ethyl acetate. The SEM photographs in Figure 3a,b show that the surface of PLA-DTY fibers is smooth and the cross section is flat. When the PLA-DTY fibers are treated with ethyl acetate, it can be seen from Figure $3 c$ that a small quantity of longitudinal grooves exists on the surface of PLA-DTY fibers. However, the change of cross section of PLA-DTY fibers is difficult to observe. The effect of ethyl acetate on PLA-DTY fibers is small because PLA-DTY fibers own high crystallinity [11]. DTY is prepared by drawing and twisting/untwisting simultaneously POY so that PLA-DTY fibers own high crystallinity. 
Figure 3d-f illustrates that in PLA-DTY fibers treated by MWCNTs and PVAc in ethyl acetate with the concentration of $8 \mathrm{mg} / \mathrm{mL}$ MWCNTs and $40 \mathrm{mg} / \mathrm{mL}$ PVAc, the single fiber of multifilaments adheres to each other. In addition, the MWCNTs are coated on the surface of PLA-DTY fibers, which can be observed in Figure 3e,f.
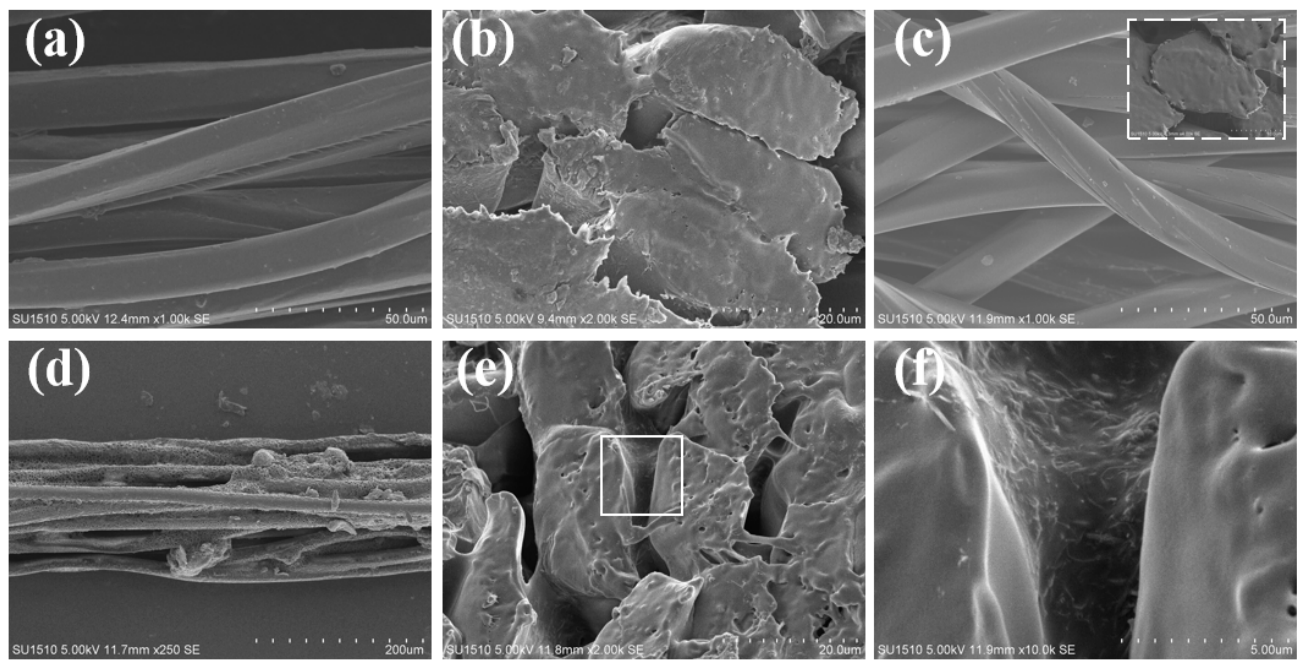

Figure 3. The SEM photographs of PLA-DTY fibers treated by MWCNTs and PVAc in ethyl acetate. (a,b) Original PLA-DTY fibers. (c) PLA-DTY fibers treated by ethyl acetate for $30 \mathrm{~min}$ at room temperature. (d,e) PLA-DTY fibers treated with MWCNTs and PVAc in ethyl acetate with concentration of $8 \mathrm{mg} / \mathrm{mL}$ MWCNTs and $40 \mathrm{mg} / \mathrm{mL}$ PVAc. (f) The enlargement of the part in white square frame of panel e.

\subsection{DSC Analysis}

The original PLA-POY fibers, original PLA-DTY fibers, and the PLA fibers treated by MWCNTs and PVAc in ethyl acetate were analyzed by DSC. The DSC curves are shown in Figure 4. Figure 4a shows that in the DSC curve of PLA-POY fibers, the glass transition district, cold crystallization peak, and melting peak can be observed. In addition, the glass transition district and cold crystallization peak overlap partly in the range of 60 to $90{ }^{\circ} \mathrm{C}$. However, in the DSC curves of the PLA-POY fibers treated by MWCNTs and PVAc in ethyl acetate, the glass transition temperature $\left(T_{g}\right)$ and cold crystallization temperature $\left(T_{c c}\right)$ disappear. This illustrates that compared with the original PLA-POY fibers, the crystallinity of the PLA-POY fibers treated by MWCNTs and PVAc in ethyl acetate increases. This is due to the ethyl acetate inducing the crystallization of PLA-POY fibers. However, Figure $4 \mathrm{~b}$ shows that compared with the original PLA-DTY fibers, an obvious change in DSC curves of PLA-DTY fibers treated by MWCNTs and PVAc in ethyl acetate cannot be observed. This illustrates that the effect of ethyl acetate on the structure of PLA-DTY fibers is small because of their high crystallinity.
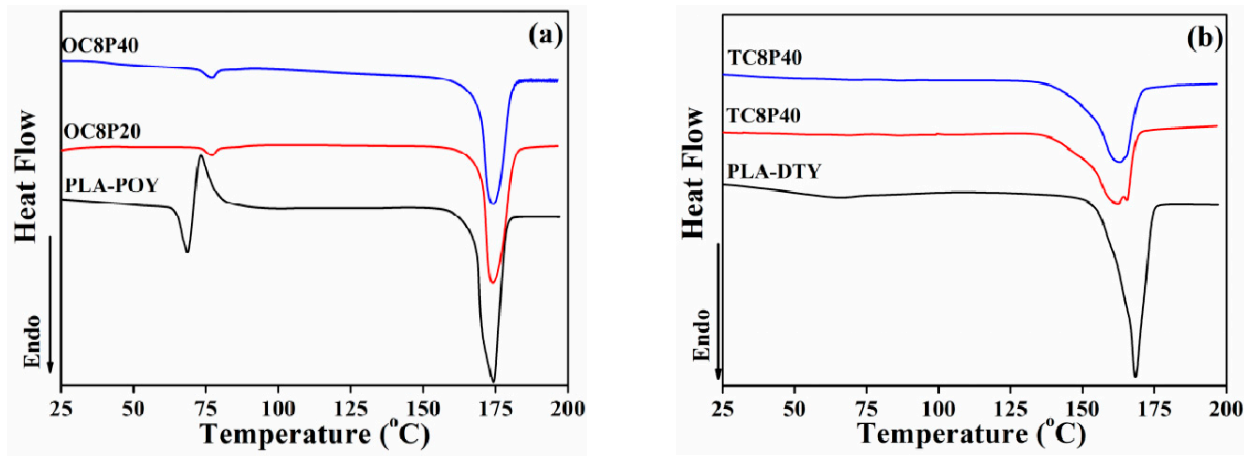

Figure 4. Differential scanning calorimetry (DSC) curves of PLA-POY (a) and PLA-DTY (b) fibers treated by MWCNTs and PVAc in ethyl acetate with $8 \mathrm{mg} / \mathrm{mL}$ MWCNTs and different PVAc concentration. 


\subsection{FTIR-ATR Analysis}

The FTIR-ATR spectra of PLA-POY fibers treated by MWCNTs and PVAc in ethyl acetate with concentration of $8 \mathrm{mg} / \mathrm{mL}$ MWCNTs, original PLA-POY fibers, and PVAc are illustrated in Figure 5. In Figure 5, for PVAc, the peak at $1729 \mathrm{~cm}^{-1}$ corresponds to the amorphous $\mathrm{C}=\mathrm{O}$ stretching. The vibration bands at $2970 \mathrm{~cm}^{-1}$ are ascribed to $\mathrm{CH}_{3}$ asymmetric stretching. The band at $2926 \mathrm{~cm}^{-1}$ corresponds to $\mathrm{CH}_{2}$ asymmetric stretching. The bands at 1433 and $1370 \mathrm{~cm}^{-1}$ correspond to asymmetic and symmetric bending vibrations of $\mathrm{CH}_{3}$, respectively. The peaks at 1225 and $1118 \mathrm{~cm}^{-1}$ are attributed to $\mathrm{C}-\mathrm{O}-\mathrm{C}$ asymmetric and symmetric vibrations, respectively. The peak at $946 \mathrm{~cm}^{-1}$ is assigned to $\mathrm{CH}$ bending vibration [15]. For PLA, the peak at $1749 \mathrm{~cm}^{-1}$ corresponds to $\mathrm{C}=\mathrm{O}$ stretching. The bands at 2995 and $2945 \mathrm{~cm}^{-1}$ are attributed to $\mathrm{CH}_{3}$ asymmetric and symmetric vibrating, respectively. The bands at $2881 \mathrm{~cm}^{-1}$ correspond to $\mathrm{CH}$ vibrating. The peaks at 1452 and $1382 \mathrm{~cm}^{-1}$ are assigned to $\mathrm{CH}_{3}$ asymmetric deformation and $\mathrm{CH}_{3}$ symmetric deformation, respectively. The peaks at 1359 or $1363 \mathrm{~cm}^{-1}$ are ascribed to $\mathrm{CH}$ deformation and crystalline $\mathrm{CH}_{3}$ symmetric deformation. The peaks at 1181,1128 , 1083 , and $1043 \mathrm{~cm}^{-1}$ correspond to $\mathrm{C}-\mathrm{O}-\mathrm{C}$ stretching, $\mathrm{CH}_{3}$ rocking, $\mathrm{C}-\mathrm{O}-\mathrm{C}$ stretching, and $\mathrm{C}-\mathrm{CH}_{3}$ stretching, respectively [16]. Figure $5 \mathrm{~b}$ shows that when the concentration of PVAc is $20 \mathrm{mg} / \mathrm{mL}$, the FTIR-ATR spectra of the treated PLA-POY fibers are similar to those of the original PLA-POY fibers. However, when the concentration of PVAc is $40 \mathrm{mg} / \mathrm{mL}$, the FTIR-ATR spectra of the treated PLA-POY fibers are similar to that of original PVAc. In addition, when the concentration of PVAc is $20 \mathrm{mg} / \mathrm{mL}$, the $\mathrm{C}=\mathrm{O}$ stretching band occurs at $1743 \mathrm{~cm}^{-1}$, which is located at the middle district between the $\mathrm{C}=\mathrm{O}$ stretching band of PLA and that of PVAc. Generally, FTIR-ATR is used to characterize the chemical structure of the surface of materials. This revealed that PLA-POY fibers are partly coated by PVAc or the PVAc layer on the surface of PLA-POY fibers is very thin. However, when the concentration of PVAc is $40 \mathrm{mg} / \mathrm{mL}$, the $\mathrm{C}=\mathrm{O}$ stretching band occurred at $1729 \mathrm{~cm}^{-1}$, which is identical to the wavenumber of $\mathrm{C}=\mathrm{O}$ in PVAc. This shows that the PLA-POY fibers have been coated completely by PVAc. The FTIR-ATR spectra of PLA-DTY fibers treated by MWCNTs and PVAc in ethyl acetate with the concentration of $8 \mathrm{mg} / \mathrm{mL}$ MWCNTs, original PLA-DTY, and PVAc are illustrated in Figure 6; similar results are found.
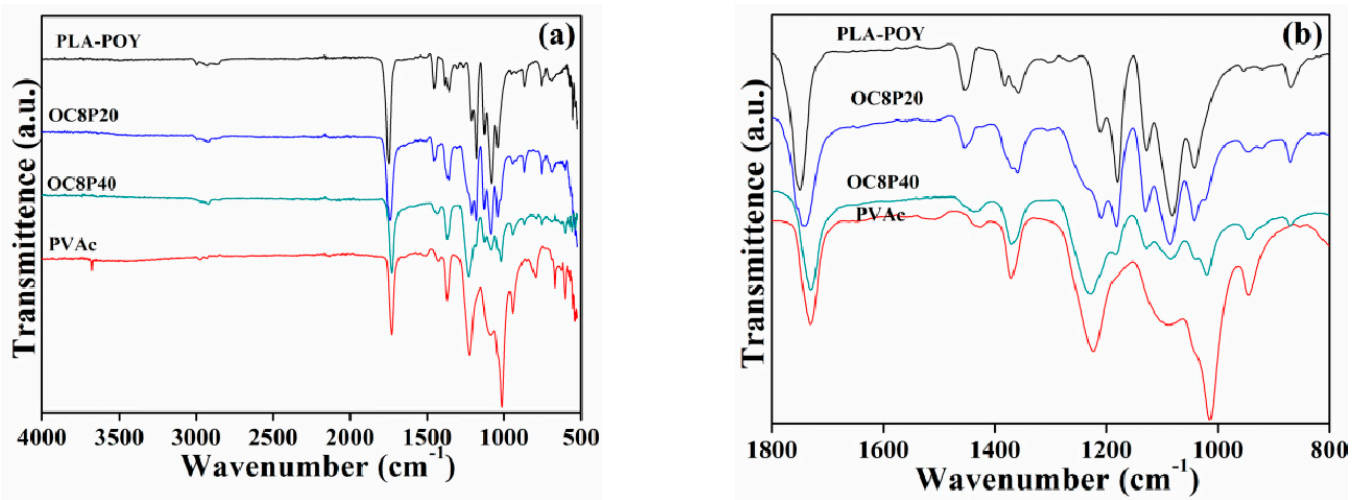

Figure 5. FTIR-ATR spectra of PLA-POY fibers treated by MWCNTs and PVAc in ethyl acetate with the concentration of $8 \mathrm{mg} / \mathrm{mL}$ MWCNTs and different PVAc concentration: (a) $4000-500 \mathrm{~cm}^{-1}$ and (b) $1800-800 \mathrm{~cm}^{-1}$. 

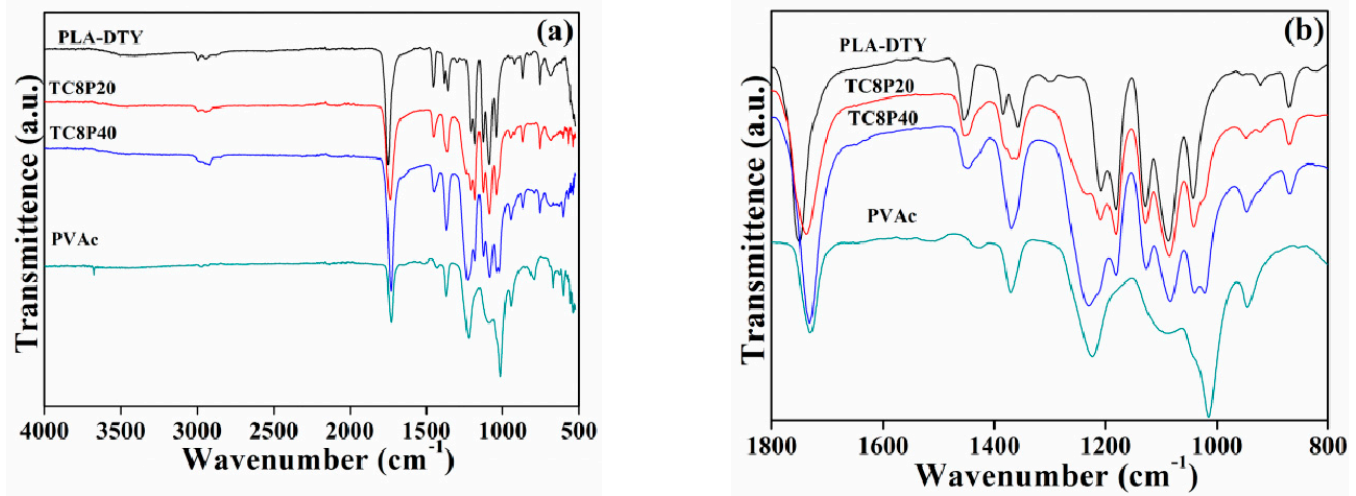

Figure 6. ATR-FTIR spectra of PLA-DTY fibers treated by MWCNTs and PVAc in ethyl acetate solution with the concentration of $8 \mathrm{mg} / \mathrm{mL}$ MWCNTs and different PVAc concentration: (a) $4000-500 \mathrm{~cm}^{-1}$ and (b) $1800-800 \mathrm{~cm}^{-1}$.

\subsection{Conductive Properties}

The conductive properties of PLA-POY and PLA-DTY fibers treated by MWCNTs and PVAc in ethyl acetate have been characterized by a Keithley 65167B high-resistance meter, TENMARS TM-87 digital multimeter, and YG321 fiber-specific resistance tester. The results of electrical conductivity are listed in Tables 1 and 2. It can be seen that the electrical conductivity of the treated PLA fibers is much higher than that of the untreated PLA fibers. The values of electrical conductivity of PLA fibers show that with the increase of the concentration of MWCNTs or PVAc, the electrical conductivity of PLA-DTY and PLA-POY fibers increases. However, when the concentration of MWCNTs is $2 \mathrm{mg} / \mathrm{mL}$, with the increase of the concentration of PVAc from 10 to $20 \mathrm{mg} / \mathrm{mL}$, the electrical conductivity of the treated PLA-POY and PLA-DTY fibers increased significantly from $1.2 \times 10^{-3}$ to $1.43 \times 10^{-2} \mu \mathrm{s} / \mathrm{cm}, 0.7$ $\times 10^{-3}$ to $8.3 \times 10^{-3} \mu \mathrm{s} / \mathrm{cm}$, respectively, whereas with the increase in concentration of PVAc from 20 to $50 \mathrm{mg} / \mathrm{mL}$, those of the PLA-POY and PLA-DTY fibers barely change from $1.43 \times 10^{-2}$ to $1.47 \times 10^{-2}$ $\mu \mathrm{s} / \mathrm{cm}$ and $8.3 \times 10^{-3}$ to $8.9 \times 10^{-3} \mu \mathrm{s} / \mathrm{cm}$, respectively. When the concentration of MWCNTs is more than $2 \mathrm{mg} / \mathrm{mL}$, the effect of PVAc on with electrical conductivity of the treated PLA-POY and PLA-DTY fibers is obvious. However, when the concentration of PVAc reaches $40 \mathrm{mg} / \mathrm{mL}$, with the further increase of the concentration of PVAc, the change of electrical conductivity of the treated PLA-POY and PLA-DTY fibers is small.

Table 1. The electrical conductivity of PLA-POY fibers treated by MWCNTs and PVAc in ethyl acetate (unit: $10^{-3} \mu \mathrm{s} / \mathrm{cm}$ ).

\begin{tabular}{cccc}
\hline Samples & Electrical Conductivity & Samples & Electrical Conductivity \\
\hline PLA-POY & $9.5 \times 10^{-5}$ & OC6P30 & 22.7 \\
OC2P10 & 1.2 & OC6P40 & 181.8 \\
OC2P20 & 14.3 & OC6P50 & 204.1 \\
OC2P30 & 14.1 & OC8P10 & 6.8 \\
OC2P40 & 14.3 & OC8P20 & 14.1 \\
OC2P50 & 14.7 & OC8P30 & 245.2 \\
OC4P10 & 5.3 & OC8P40 & 409.6 \\
OC4P20 & 13.7 & OC8P50 & 371.4 \\
OC4P30 & 15.6 & OC10P10 & 7.7 \\
OC4P40 & 21.7 & OC10P20 & 14.1 \\
OC4P50 & 37.0 & OC10P30 & 129.1 \\
OC6P10 & 15.4 & OC10P40 & 270.3 \\
OC6P20 & 17.2 & OC10P50 & 526.3 \\
\hline
\end{tabular}


Table 2. The electrical conductivity of PLA-DTY fibers treated by MWCNTs and PVAc in ethyl acetate (unit: $10^{-3} \mu \mathrm{s} / \mathrm{cm}$ ).

\begin{tabular}{cccc}
\hline Samples & Electrical Conductivity & Samples & Electrical Conductivity \\
\hline PLA-DTY & $1.1 \times 10^{-4}$ & TC6P30 & 14.0 \\
TC2P10 & 0.7 & TC6P40 & 60.5 \\
TC2P20 & 8.3 & TC6P50 & 106.6 \\
TC2P30 & 8.8 & TC8P10 & 4.0 \\
TC2P40 & 8.9 & TC8P20 & 9.0 \\
TC2P50 & 8.9 & TC8P30 & 76.8 \\
TC4P10 & 2.7 & TC8P40 & 103.7 \\
TC4P20 & 8.5 & TC8P50 & 127.0 \\
TC4P30 & 9.4 & TC10P10 & 4.8 \\
TC4P40 & 39.2 & TC10P20 & 9.0 \\
TC4P50 & 73.9 & TC10P30 & 69.2 \\
TC6P10 & 3.6 & TC10P40 & 118.0 \\
TC6P20 & 9.7 & TC10P50 & 130.8 \\
\hline
\end{tabular}

When the concentration of PVAc is $10 \mathrm{mg} / \mathrm{mL}$, with the increase of the concentration of MWCNTs from 2 to $4 \mathrm{mg} / \mathrm{mL}$, the electrical conductivity of the treated PLA-POY and PLA-DTY fibers increases significantly from $1.2 \times 10^{-3}$ to $5.3 \times 10^{-3} \mu \mathrm{s} / \mathrm{cm}$ and $0.7 \times 10^{-3}$ to $2.7 \times 10^{-3} \mu \mathrm{s} / \mathrm{cm}$, respectively; whereas, with the increase of the concentration of MWCNTs from 4 to $10 \mathrm{mg} / \mathrm{mL}$, those of the PLA-POY and PLA-DTY fibers increase inapparently from $5.3 \times 10^{-3}$ to $7.7 \times 10^{-3} \mu \mathrm{s} / \mathrm{cm}$, and $2.7 \times 10^{-3}$ to 4.8 $\times 10^{-3} \mu \mathrm{s} / \mathrm{cm}$, respectively. When the concentration of PVAc is $20 \mathrm{mg} / \mathrm{mL}$, with the increase of the concentration of MWCNTs from 2 to $10 \mathrm{mg} / \mathrm{mL}$, the electrical conductivity of the treated PLA-POY and PLA-DTY fibers almost does not change. However, when the concentration of MWCNTs is more than $30 \mathrm{mg} / \mathrm{mL}$, the effect of MWCNTs on the electrical conductivity of the treated PLA-POY and PLA-DTY fibers is significant. However, when the concentration of MWCNTs is more than $8 \mathrm{mg} / \mathrm{mL}$, with the further increase of the concentration of MWCNTs, the change of electrical conductivity of the treated PLA-POY and PLA-DTY fibers is not obvious.

Here, MWCNTs are used as the conductive additives. Therefore, with the increase in the concentration of MWCNTs, the conductive network can easily form so that the conductive properties increase. PVAc is used as a dispersing agent to make the MWCNTs disperse uniformly in ethyl acetate. Therefore, with the increase of PVAc, MWCNTs can be efficiently used by dispersing MWCNTs uniformly in ethyl acetate so that the conductive properties increase. When the concentration of MWCNTs is low $(2 \mathrm{mg} / \mathrm{mL})$, the PVAc concentration of $10 \mathrm{mg} / \mathrm{mL}$ is enough large to make MWCNTs disperse uniformly in ethyl acetate, so that further increasing the concentration of PVAc cannot improve the conductivity of the PLA fibers. In addition, when the concentration of PVAc is low (less than $20 \mathrm{mg} / \mathrm{mL}$ ), it is difficult to make a large number of MWCNTs uniformly in ethyl acetate. Therefore, MWCNTs cannot be used efficiently, thus further increasing the concentration is meaningless.

\subsection{Tensile Properties}

Figure 7 illustrates the curves of load-strain relationship of PLA-POY fibers treated by MWCNTs and PVAc in ethyl acetate. The values of tensile force $(F)$, elongation at break $(\varepsilon)$, and work of rupture $(W)$ are listed in Table 3. As can be seen in Figure 7, the original PLA-POY fibers and treated PLA-POY fibers present a typical tough fracture. It can be seen from Figure 7 and Table 3 that the tensile force of the treated PLA-POY fibers is much higher than that of the original PLA-POY fibers. The reason is as follows; the PLA-POY fibers have relatively low crystallinity when the PLA-POY fibers are treated by MWCNTs and PVAc in ethyl acetate. The ethyl acetate first will make amorphous district of the PLA-POY fibers swell. Then, when the PLA-POY fibers are taken out from the solution, ethyl acetate will evaporate to induce crystallization of PLA-POY fibers to form a highly porous structure, which makes the tensile force decrease obviously. 

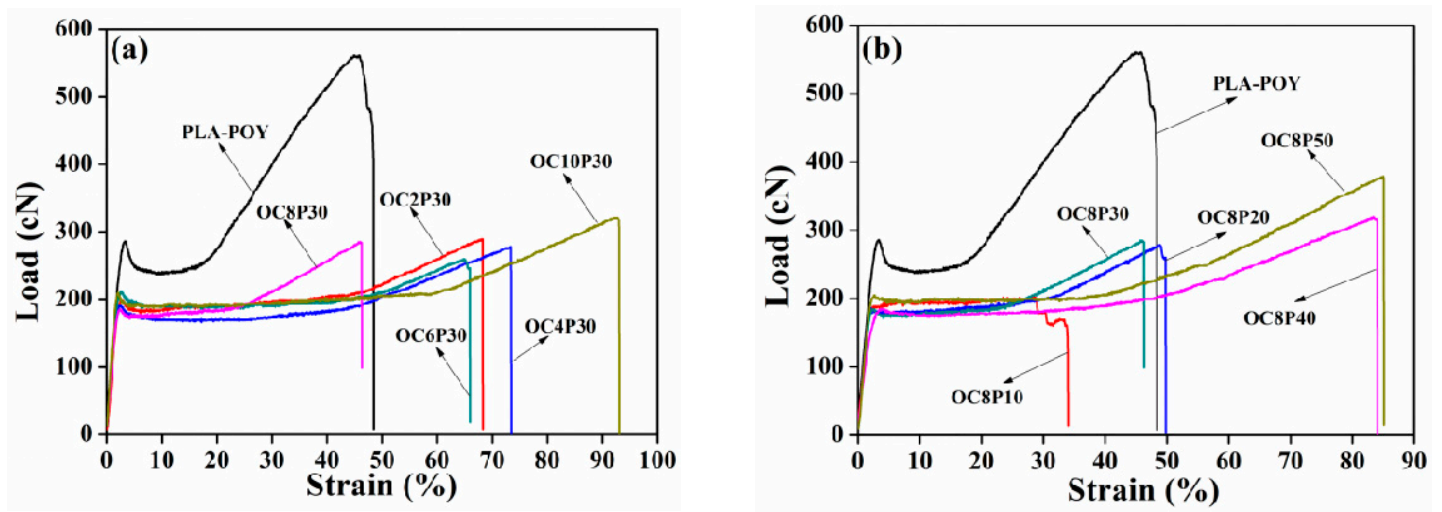

Figure 7. Tensile properties of PLA-POY fibers treated by MWCNTs and PVAc in ethyl acetate: (a) $30 \mathrm{mg} / \mathrm{mL}$ PVAc and (b) $8 \mathrm{mg} / \mathrm{mL}$ MWCNTs.

Table 3. Tensile properties of PLA-POY fibers treated by MWCNTs and PVAc in ethyl acetate.

\begin{tabular}{cccc}
\hline Samples & Tensile Force $(\mathbf{c N})$ & Elongation at Break $\mathbf{( \% )}$ & Work of Rupture $(\mathbf{J})$ \\
\hline PLA-POY & $566 \pm 9$ & $46 \pm 1$ & $0.40 \pm 0.02$ \\
OC2P30 & $304 \pm 60$ & $67 \pm 14$ & $0.4 \pm 0.1$ \\
OC4P30 & $286 \pm 13$ & $73 \pm 6$ & $0.36 \pm 0.04$ \\
OC6P30 & $251 \pm 67$ & $61 \pm 16$ & $0.3 \pm 0.1$ \\
OC8P30 & $288 \pm 32$ & $49 \pm 3$ & $0.25 \pm 0.03$ \\
OC10P30 & $318 \pm 20$ & $95 \pm 9$ & $0.51 \pm 0.05$ \\
OC8P10 & $211 \pm 10$ & $41 \pm 22$ & $0.2 \pm 0.1$ \\
OC8P20 & $320 \pm 53$ & $53 \pm 12$ & $0.29 \pm 0.08$ \\
OC8P40 & $347 \pm 35$ & $81 \pm 12$ & $0.45 \pm 0.09$ \\
OC8P50 & $401 \pm 54$ & $87 \pm 14$ & $0.6 \pm 0.1$ \\
\hline
\end{tabular}

Figure 7a and Table 3 illustrate that when the concentration of PVAc is $30 \mathrm{mg} / \mathrm{mL}$, the effect of MWCNTs concentration on tensile properties of PLA-POY fibers is small. However, Figure $7 \mathrm{~b}$ and Table 3 show that when the concentration of MWCNTs is $8 \mathrm{mg} / \mathrm{mL}$, with the increase of PVAc concentration from 10 to $50 \mathrm{mg} / \mathrm{mL}$, the tensile force, strain, and work of rupture of the PLA-POY fibers increase from 211 to $401 \mathrm{cN}, 41 \%$ to $87 \%$, and 0.2 to $0.6 \mathrm{~J}$, respectively. The reason is as follows; PVAc and PLA are compatible completely when the PLA-POY fibers are treated by MWCNTs and PVAc in ethyl acetate. The PVAc will coat the PLA-POY fibers and fill the pores to improve the tensile property of PLA-POY.

In addition, the curve of the PLA-POY fibers treated by MWCNTs and PVAc in ethyl acetate with $8 \mathrm{mg} / \mathrm{mL}$ MWCNTs and $10 \mathrm{mg} / \mathrm{mL}$ (OC8P10) is different from those of the PLA-POY fibers treated by MWCNTs and PVAc in ethyl acetate with more than $20 \mathrm{mg} / \mathrm{mL}$. The latter owns an obvious stress-hardening district, whereas the stress-hardening district cannot be observed in the former, because the content of PVAc in the former is low. This further shows that the PVAc and PLA fibers have good adhesive force. PVAc can improve the tensile properties of highly porous PLA-POY fibers.

Figure 8 illustrates the curves of load-strain relationship of PLA-DTY fibers treated by MWCNTs and PVAc in ethyl acetate. The values of tensile force $(F)$, elongation at break $(\varepsilon)$, and work of rupture $(W)$ are listed in Table 4. Figure 8 shows that the curve of original PLA-DTY fibers has a similar shape to those of the treated PLA-DTY fibers; they present a typical tough fracture. It can be seen from Figure 8 and Table 4 that the tensile force of the treated PLA-DTY fibers is larger than that of original PLA-DTY fiber. The reason is as follows; the effect of ethyl acetate on PLA-DTY is small, and the PVAc on the surface of PLA-DTY fiber can improve the mechanical properties. However, Figure $8 \mathrm{~b}$ shows that with the increase of PVAc, the tensile properties of the treated PLA-DTY fibers almost do not change. 

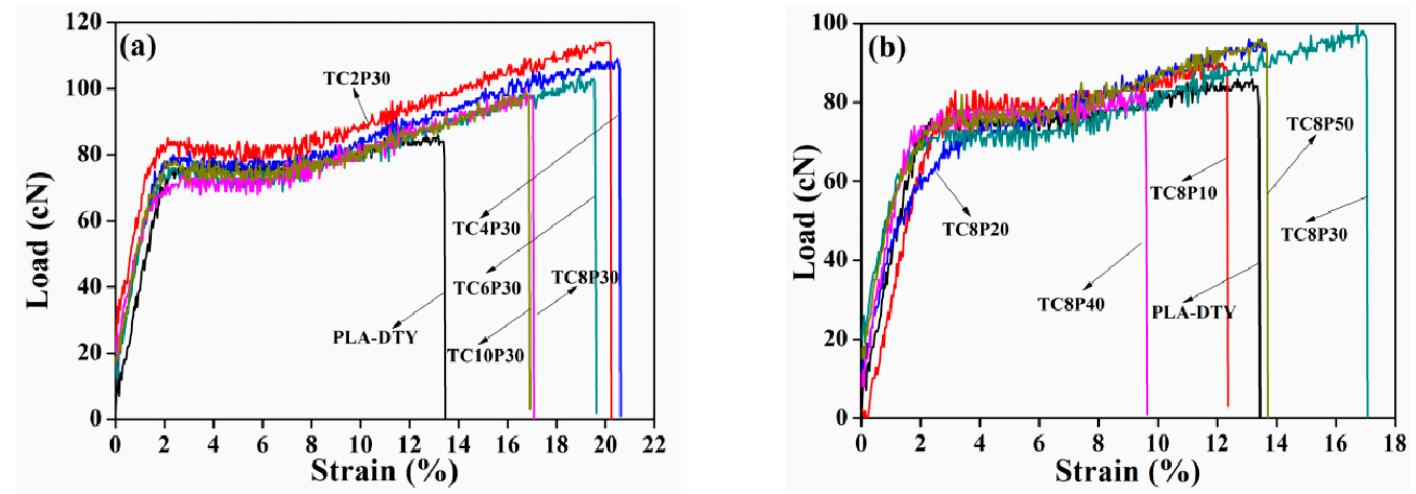

Figure 8. Tensile properties of PLA-DTY fibers treated by MWCNTs and PVAc in ethyl acetate: (a) $30 \mathrm{mg} / \mathrm{mL}$ PVAc and (b) $8 \mathrm{mg} / \mathrm{mL}$ MWCNTs.

Table 4. Tensile properties of PLA-DTY fibers treated by MWCNTs and PVAc in ethyl acetate.

\begin{tabular}{cccc}
\hline Samples & Tensile Force $(\mathbf{c N})$ & Elongation at Break $(\%)$ & Work of Rupture $(\mathbf{J})$ \\
\hline PLA-DTY & $85.0 \pm 0.8$ & $12.6 \pm 0.4$ & $0.022 \pm 0.001$ \\
TC2P30 & $111 \pm 6$ & $19 \pm 3$ & $0.041 \pm 0.009$ \\
TC4P30 & $107 \pm 4$ & $19 \pm 2$ & $0.041 \pm 0.006$ \\
TC6P30 & $103 \pm 2$ & $19 \pm 1$ & $0.037 \pm 0.002$ \\
TC8P30 & $96 \pm 5$ & $16 \pm 3$ & $0.030 \pm 0.006$ \\
TC10P30 & $98 \pm 6$ & $16 \pm 2$ & $0.031 \pm 0.005$ \\
TC8P10 & $94 \pm 4$ & $13 \pm 2$ & $0.024 \pm 0.005$ \\
TC8P20 & $95 \pm 7$ & $15 \pm 3$ & $0.027 \pm 0.007$ \\
TC8P40 & $86 \pm 4$ & $10 \pm 2$ & $0.018 \pm 0.004$ \\
TC8P50 & $95 \pm 4$ & $14 \pm 2$ & $0.026 \pm 0.005$ \\
\hline
\end{tabular}

It can be seen from Table 3 that for PLA-POY, the tensile properties of the treated PLA fibers are much smaller than those of the untreated PLA fibers. However, it is exciting that OC8P40 and OC8P50, both with high electrical conductivity, own high tensile properties (Tables 1 and 3). For PLA-DTY, although the tensile properties of the treated PLA fibers are much larger than those of the untreated PLA fibers (Table 4), the TC8P50 with the highest electrical conductivity does not have the highest strength (Tables 2 and 4). However, the difference between the tensile strength of TC8P50 and the highest strength is small. Therefore, it can be concluded that PLA-POY and PLA-DTY, both with high electrical conductivity, own satisfactory tensile properties.

\section{Conclusions}

The conductive PLA-POY and PLA-DTY fibers are produced successfully by coating method using ethyl acetate as solvent, MWCNTs as conductive filler, and PVAc as dispersing agent and coating agent. The PLA fibers are characterized by SEM, FTIR, DSC, resistance meter, and tensile test. The larger the PVAc concentration is, the more uniformly the MWCNTs disperse in ethyl acetate. MWCNTs have successfully coated the surface of PLA-POY and PLA-DTY fibers. The highly porous structures form when PLA-POY fibers are treated by ethyl acetate, decreasing the tensile forces. The tensile force of original PLA-POY fibers is $566 \mathrm{cN}$, whereas that of the treated PLA-POY fibers ranges from 211 to $401 \mathrm{cN}$. However, the PVAc can improve the tensile force of the treated PLA-POY fibers. When the concentration of MWCNTs is $8 \mathrm{mg} / \mathrm{mL}$, coupled with the increase of PVAc concentration from 10 to $50 \mathrm{mg} / \mathrm{mL}$, the tensile force of the PLA-POY fibers increases from 211 to $401 \mathrm{cN}$. For PLA-DTY fibers, the effect of ethyl acetate on surface morphology is small. Therefore, the treated PLA-DTY fibers own higher tensile properties. With the increase of PVAc and MWCNTs, the conductive properties of the PLA fibers increase. The electrical conductivity of PLA-POY and PLA-DTY fibers can reach 0.53 and $0.13 \mu \mathrm{s} / \mathrm{cm}$, respectively. 
Author Contributions: Formal Analysis, Q.L. and Y.Z.; Investigation, Q.L., Y.Z. and Y.S.; Data Curation, Y.Z.; Writing-Original Draft Preparation, Q.L.; Writing-Review and Editing, Q.L. and B.D.; Supervision, Q.L., Y.L. (Yuhao Li), H.G. and Y.L. (Yonggui Li); Funding Acquisition, H.G. and Y.L. (Yonggui Li).

Funding: This research was supported by the Equipment Pre-Research Fund (61409220412); the Chinese Postdoctoral Science Foundation (2019M651699); the National Defense Cultivation Project of Fundamental Research Funds for the Central Universities (JUSRP41904); the Key Research and Development Program (Industry Forward and Common Key Technology) of Suqian City (H201708); the Open Project Program of Fujian Key Laboratory of Novel Functional Textile Fibers and Materials, Minjiang University, China (FKLTFM1714); the Jiangsu Overseas Research Training Program for University Prominent Young and Middle-Aged Teachers and Presidents; the Foundation of Key Laboratory of Pulp and Paper Science and Technology of Ministry of Education/Shandong Province of China (KF201714); the 111 Project (B17021); the Priority Academic Program Development of Jiangsu Higher Education Institutions; and the Top-Notch Academic Programs Project of Jiangsu Higher Education Institutions (PPZY2015B147).

Conflicts of Interest: The authors declare no conflicts of interest.

\section{References}

1. Liu, Q.S.; Zhao, M.M.; Zhou, Y.Q.; Yang, Q.B.; Shen, Y.; Gong, R.H.; Zhou, F.L.; Deng, B.Y. Polylactide single-polymer composites with a wide melt-processing window based on core-sheath PLA fibers. Mater. Des. 2018, 139, 36-44. [CrossRef]

2. Liu, Q.S.; Wu, C.; Zhang, H.X.; Deng, B.Y. Blends of polylactide and poly(3-hydroxybutyrate-co-3-hydroxyvalerate) with low content of hydroxyvalerate unit: Morphology, structure, and property. J. Appl. Polym. Sci. 2015, 132, 42689. [CrossRef]

3. Liu, Q.S.; Sun, Y.Y.; Xia, S.N.; Zhang, H.X.; Tao, X.L.; Liu, Y.Y.; Deng, B.Y. Structure and mechanical property of polylactide fibers manufactured by air drawing. Text. Res. J. 2016, 86, 948-959. [CrossRef]

4. Schmack, G.; Tändler, B.; Optiz, G.; Vogel, R.; Komber,H.; Häußler, L.; Voigt, D.; Weinmann, S.; Heinemann, M.; Fritz, H.-G. High-speed melt spinning of various grades of polylactides. J. Appl. Polym. Sci. 2004, 91, 800-806. [CrossRef]

5. Takasaki, M.; Ito, H.; Kikutani, T. Development of stereocomplex crystal of polylactide in high-speed melt spinning and subsequent drawing and annealing process. J. Macromol. Sci. Part B Phys. 2003, B42, 403-420. [CrossRef]

6. Furuhashi, Y.; Kimura, Y.; Yamane, H. Higher order structural analysis of stereocomplex-type poly(lactic acid) melt-spun fibers. J. Polym. Sci. Part B Polym. Phys. 2007, 45, 218-228. [CrossRef]

7. Solarski, S.; Mahjoubi, F.; Ferreira, M.; Devaux, E.; Bachelet, P.; Bourbigot, S.; Delobel, R.; Coszach, P.; Murariu, M.; Ferreira, A.D.S.; et al. (Plasticized) Polylactide/clay nanocomposite textile: Thermal mechanical, shrinkage and fire properties. J. Mater. Sci. 2007, 42, 5105-5117. [CrossRef]

8. Li, L.Z.; Huang, W.; Wang, B.J.; Wei, W.F.; Gu, Q. Properties and structure of polylactide/poly (3-hydroxybutyrate-co-3-hydroxyvalerate) (PLA/PHBV) blend fibers. Polymer 2015, 68, 183-194. [CrossRef]

9. Hufenus, R.; Reifler, F.A.; Maniura-Weber, K.; Spierings, A.; Zinn, M. Biodegradable bicomponent fibers from renewable sources: Melt-spinning of poly(lactic acid) and poly[(3-hydroxybutyrate)-co-(3-hydroxyvalerate)]. Macromol. Mater. Eng. 2012, 297, 75-84. [CrossRef]

10. Zhang, H.X.; Bai, H.W.; Liu, Z.W.; Zhang, Q.; Fu, Q. Toward high-performance poly(L-lactide) fibers via tailoring crystallization with the aid of fibrillar nucleating agent. ACS Sustain. Chem. Eng. 2016, 4, 3939-3947. [CrossRef]

11. Liu, Q.S.; Yang, Q.B.; Zhou, Y.Q.; Zhao, M.M.; Shen, Y.; Zhou, F.L.; Gong, R.H.; Deng, B.Y. A facile method of preparing highly porous polylactide microfibers. J. Appl. Polym. Sci. 2018, 135, 45860. [CrossRef]

12. Rentenberger, R.; Cayla, A.; Villmow, T.; Jehnichen, D.; Campagne, C.; Rochery, M.; Devaux, E.; Pötschke, P. Multifilament fibres of poly( $\varepsilon$-caprolactone)/poly(lactic acid) blends with multiwalled carbon nanotubes as sensor materials for ethyl acetate and acetone. Sens. Actuat. B Chem. 2011, 160, 22-31. [CrossRef]

13. Zhang, X.H.; Lu, W.B.; Zhou, G.H.; Li, Q.W. Understanding the Mechanical and Conductive Properties of Carbon Nanotube Fibers for Smart Electronics. Adv. Mater. 2019, 1902028. [CrossRef] [PubMed]

14. Zhao, Y.T.; Sun, X.T.; Zhao, H.T.; Tian, M.W.; Zhang, X.S.; Zhu, S.F. A simple and scalable production of conductive fibers with excellent washing resistance. Mater. Lett. 2019, 239, 9-12. [CrossRef] 
15. Liu, Q.S.; Jiang, J.Z.; Zhang, H.X.; Wang, J.C.; Li, X.M.; Li, Y.H.; Deng, B.Y. Miscibility and phase morphology of polylactide/poly(vinyl acetate-co-vinyl alcohol) blends obtained by melt mixing. Polym.-Plast. Technol. 2014, 53, 1590-1597. [CrossRef]

16. Liu, Q.S.; Zhang, H.X.; Zhu, M.F.; Dong, Z.; Wu, C.; Jiang, J.Z.; Li, X.R.; Luo, F.; Gao, Y.X.; Deng, B.Y.; et al. Blends of polylactide/thermoplactic elastomer: Miscibility, physical aging and crystallization behaviors. Fibers Polym. 2013, 14, 1688-1698. [CrossRef]

(C) 2019 by the authors. Licensee MDPI, Basel, Switzerland. This article is an open access article distributed under the terms and conditions of the Creative Commons Attribution (CC BY) license (http://creativecommons.org/licenses/by/4.0/). 